Journal of Advanced Research in Fluid Mechanics and Thermal Sciences

Journal homepage: www.akademiabaru.com/arfmts.html ISSN: 2289-7879

\title{
Internal Combustion Engine Exhaust Waste Heat Recovery Using Thermoelectric Generator Heat Exchanger
}

\author{
Nor Amelia Shafikah Mat Noh ${ }^{1}$, Baljit Singh Bhathal Singh ${ }^{1,}{ }^{*}$, Muhammad Fairuz Remeli ${ }^{1}$, Amandeep \\ Oberoi $^{2}$ \\ Fakulti Kejuruteraan Mekanikal, Universiti Teknologi MARA, 40450 Shah Alam, Selangor, Malaysia \\ Department of Mechanical Engineering, Thapar Institute of Engineering and Technology, Patiala, India
}

\begin{tabular}{l} 
ARTICLE INFO $\quad$ ABSTRACT \\
\hline
\end{tabular}

\section{Article history:}

Received 25 August 2020

Received in revised form 22 December 2020

Accepted 23 December 2020

Available online 30 April 2021

\section{Keywords:}

Thermoelectric generator; waste heat recovery; internal combustion engine; efficiency

\begin{abstract}
Heat engine converts chemical engine available in fuel to useful mechanical energy. One of the most famous heat engines is internal combustion (IC) engine. IC engine plays a pivotal role in transportation and other industrial applications. A lot of waste heat is rejected from a typical IC engine as the conversion efficiency of this type of engine is only about 35-40\%. The waste heat has the potential to be tapped and converted into useful energy. This can help to increase the performance of the IC engine system. This work focused on the conversion of the waste heat energy of the IC engine into electricity by using thermoelectric generator (TEG). The aim of the project was to demonstrate the applicability of TEG to convert waste heat from exhaust to useful electrical energy. Two TEGs were individually tested to attain the electrical characterization and also tested on series and parallel connections. The study showed that the series connection of TEGs has improved and increased voltage generation but parallel connection is more reliable. The system proved that the waste heat recovery using TEGs has tremendous application in IC engine for better and higher efficient engine performance.
\end{abstract}

\section{Introduction}

An internal combustion engine (IC engine) is a heat engine in which the combustion of a fuel occurs. In the combustion chamber the fuel mixed with air that produces the working fluid. The reaction in the combustion channel will transform the chemical energy into mechanical work. An analysis of the European Commission showed that the percentage of $80 \%$ of the greenhouse gases in the atmosphere is composed of carbon dioxide. $25 \%$ parts of this carbon dioxide in the atmosphere is produced by transportation sector which is caused by the burning of fossil fuels in an internal combustion engine [1]. In the internal combustion engine system, the conventional efficiency is nearly about $30-35 \%$ while the rest of the energy is expelled through waste heat dissipation into the atmosphere and lost as engine cooling. One way to minimize the energy losses in an IC engine is by

\footnotetext{
* Corresponding author.

E-mail address: baljit@uitm.edu.my
}

https://doi.org/10.37934/arfmts.82.2.1527 
recovering the waste heat in the internal combustion engine. It will also maximize the efficiency of the overall performance of the IC engine. It would be possible to reduce fuel consumption by around $10 \%$ and help in improving not just the IC engine, but also the hybrid electrical vehicle in terms of energy recovery from waste heat $[2,3]$. A waste heat source that can be recovered in the engine is the energy released in the coolant system and exhaust gas. The heat rejected through the exhaust is at high temperature compared to heat loss through the engine coolant. It shows the possibility of the waste heat recovery from exhaust heat by using a thermoelectric generator [4]. The average temperature of the exhaust system of a typical IC engine is in a range of $300{ }^{\circ} \mathrm{C}$ to $500{ }^{\circ} \mathrm{C}$. However, the system can reach a temperature of $1200{ }^{\circ} \mathrm{C}$ when there is a constriction in the exhaust system [5]. Waste heat can be recovered through the method of capturing and transferring the waste heat from a process with a gas or liquid back to the system as an extra energy source. The heat generated in the IC engine can be categorized as a high temperature where the temperature is above $400{ }^{\circ} \mathrm{C}$. The higher the temperature range, the higher the quality of the waste heat and it is easier for utilization of the waste heat recovery process [6].

Thermoelectric generator (TEG) is a solid device that can be used to recover the waste heat from the IC engine to electrical power. It will convert directly thermal energy into electrical energy. The thermoelectric generator also operates quietly with no moving part as it a solid device [7]. The operating principle of TEG is based on the Seebeck whereby the generated electricity based on the temperature gradient between the hot and cold side of TEG. The temperature differential from the hot and cold source is applied across the face of modules of TEG. Thermoelectric generators that work on Seebeck effect have efficiencies around 5-10\% [8].

A heat exchanger is usually defined as the device that allows the passing of heat from a fluid to the other fluid without mixing with each other. The heat from the exhaust will transmit into the heat exchanger. The shape and size of the heat exchanger will affect the distribution profile of heat velocity [9]. Higher the velocity of heat implies the higher coefficient of heat transfer due to the increasing speed of gas. The heat exchanger developed by the previous experiment improved the efficiency of the system for waste heat conversion from IC engine. In this test, a simple heat exchanger was used to test the power generation from TEGs. TEGs were also tested on various array configurations (series and parallel). The experimental work conducted was aimed at comparing the output of TEGs based on the different electrical connections of the thermoelectric generator.

For internal combustion engines based on light duty applications, TEG waste heat recovery shows many promising applications when compared to Rankine cycle waste heat recovery, as Rankine cycle technology relies on a lot of moving parts that give rise to high dynamic forces [10]. Based on Kim et al., [11], a radiator of a light duty vehicle was modified using heat pipe. The use of heat pipes and TEGs allowed for heat transfer and power production without introducing extra moving parts. The system consisted of 72 TEGs ( $40 \mathrm{~mm}$ by $40 \mathrm{~mm}$ ). When run in the driving mode of $80 \mathrm{~km} / \mathrm{h}$, the hot side of TEG was approximately at $90{ }^{\circ} \mathrm{C}$ and the cold side was approximately at $45^{\circ} \mathrm{C}$. During these conditions $75 \mathrm{~W}$ were generated from the TEGs. Waste heat from exhaust system of internal combustion engine with the help of heat pipes and water heat sink was also applied for light duty application vehicles [12-14]. These systems are capable of generating electrical power of more than $300 \mathrm{~W}$ from light duty application vehicles. Table 1 shows some technologies based on waste heat recovery from IC engine using TEGs. 


\section{Table 1}

Studies on waste heat recovery from the IC engine using TEG

\begin{tabular}{|c|c|c|}
\hline Years & Waste Heat Recovery System & Results \\
\hline 2011 & $\begin{array}{l}\text { Kumar et al., [9] researched in waste heat recovery using } 9 \text { TEGs that } \\
\text { were electrically connected in a series in an IC engine system. The } \\
\text { heat source from the exhaust system supplied and the coolant used } \\
\text { in the engine cooling system circulated in a TEG heat exchanger as } \\
\text { shown in Figure } 1 .\end{array}$ & $\begin{array}{l}\text { The highest power output } \\
\text { achieved was } 70 \mathrm{~W} \text { at } 120 \\
{ }^{\circ} \mathrm{C} \text {. }\end{array}$ \\
\hline 2012 & $\begin{array}{l}\text { Love et al., [15] studied on exhaust heat recovery with five } \mathrm{Bi}_{2} \mathrm{Te}_{3} \\
\text { thermoelectric devices placed in between the two stainless steel heat } \\
\text { exchangers. The engine was operated at a speed of } 1500 \mathrm{rpm} \text { and } \\
70 \% \text { load. The engine coolant was used for the cooling section of the } \\
\text { heat exchanger. }\end{array}$ & $\begin{array}{l}\text { The highest temperature } \\
\text { supplied in the exhaust } \\
\text { was } 280^{\circ} \mathrm{C} \text { and coolant } \\
\text { temperature was at } 40^{\circ} \mathrm{C} \\
\text { that resulted in } 3.8 \mathrm{~W} .\end{array}$ \\
\hline 2014 & $\begin{array}{l}\text { The study on heat recovery by Karuppaiah et al., [16] in exhaust } \\
\text { system based on design and analysis of TEG with the heat exchanger } \\
\text { material used. Waste gas present in the IC engine as a hot } \\
\text { temperature source and air cooling system contact with an aluminum } \\
\text { fin that produced the temperature difference for the TEG. }\end{array}$ & $\begin{array}{l}\text { The exhaust temperature } \\
\text { varies at } 145^{\circ} \mathrm{C} \text { until } 175 \\
{ }^{\circ} \mathrm{C} \text { that resulted in } 17.5 \mathrm{~V} \\
\text { maximum voltage. }\end{array}$ \\
\hline 2015 & $\begin{array}{l}\text { Chandy et al., [17] studied-on design and analysis of heat exchanger } \\
\text { for automotive exhaust based on TEG. Two TEGs connected in series } \\
\text { and attached to two heat exchangers and the exhaust gas supplied } \\
\text { the heat in the system. The automotive air condition evaporator side } \\
\text { provided the cooling to the heat exchanger. }\end{array}$ & $\begin{array}{l}\text { The result obtained in } \\
100{ }^{\circ} \mathrm{C} \text { of temperature } \\
\text { difference that produced } \\
0.534 \mathrm{~V} \text { of voltage. }\end{array}$ \\
\hline 2015 & $\begin{array}{l}\text { Liu et al., [18] conducted the study on performance analysis of waste } \\
\text { heat recovery in the automotive system by TEG. Exhaust pipe } \\
\text { supplied heat source to four TEGs connected in parallel. The cooling } \\
\text { water tanks acted as the cooling source for the system. }\end{array}$ & $\begin{array}{l}\text { The output power } \\
\text { obtained was } 600 \mathrm{~mW} \text { at } \\
182^{\circ} \mathrm{C} \text { of temperature } \\
\text { difference. }\end{array}$ \\
\hline
\end{tabular}

\section{Methodology}

The objectives of this project are to determine the maximum power of the thermoelectric generator in IC engine applications and to evaluate the performance of the thermoelectric generator in different electrical connections. In order to achieve the objectives above, the suitable test bench was developed to improve the speed of the airflow. The flow of the project divided into two major parts which are the development of heat exchanger and installation setup of the experiment.

\subsection{Development of Heat Exchanger}

A heat exchanger (HEX) is a main part of the test section in this experiment that transfers heat from heat source. In this experiment as shown in Figure 2, the new development of heat exchanger as the improvement from the previous project to improve the maximum power extracted from TEG that is attached to a hot surface. The concept of the heat exchanger is to increase the speed of hot airflow along the transition from the inlet to the outlet of the heat exchanger to avoid fluid spread 
to the surrounding. The improvement of the heat exchanger design for a proper hot airflow channel to receive from the heat source. A reducer was added to the inlet channel which was the same size with the heat gun nozzle. Therefore it can reduce the airflow losses to the surrounding. The surface of the heat exchanger and reducer were covered with a heat insulator to prevent the heat from escaping from the heat exchanger wall. Figure 3 shows the heat exchanger with cooiling heat sink and insulation attached. The parameters of the heat exchanger is shown in Table 2.

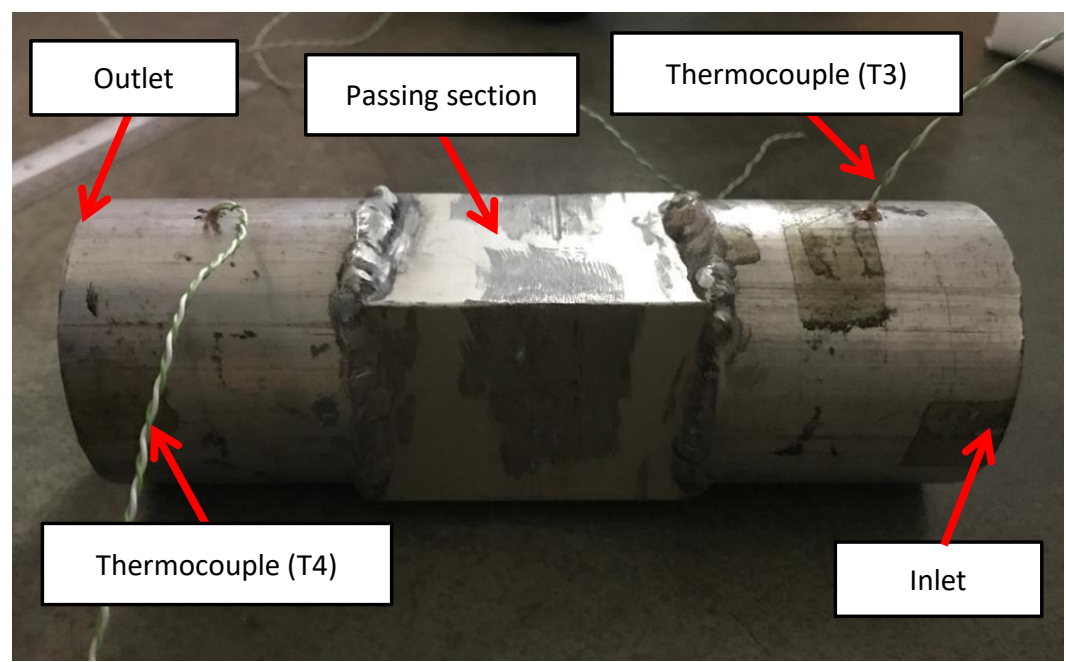

Fig. 2. Heat exchanger

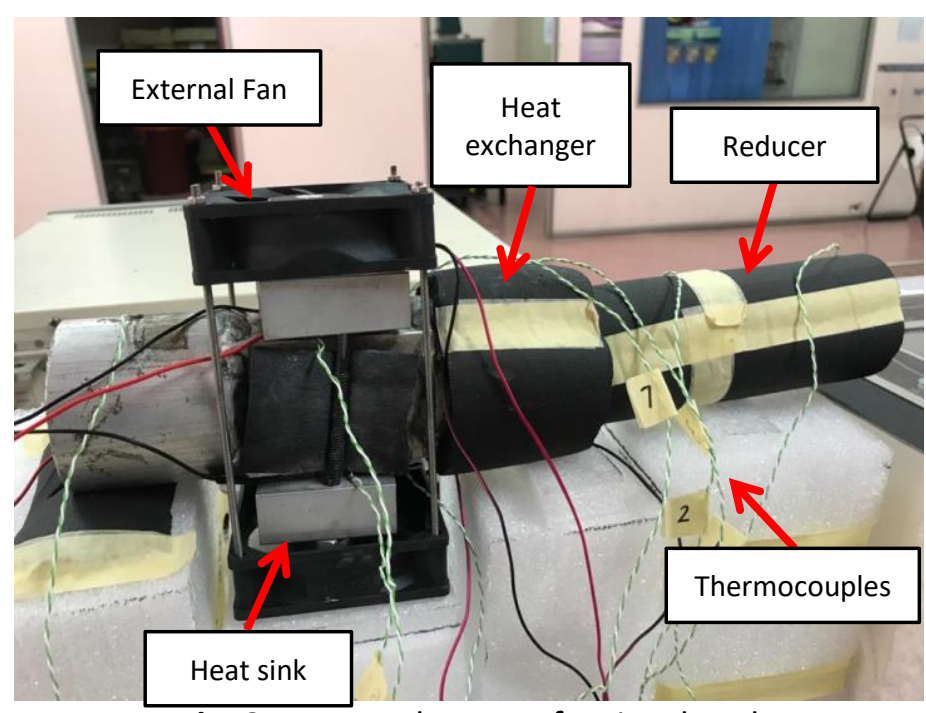

Fig. 3. Heat exchanger after insulated 


\section{Table 2}

Parameters of heat exchanger and reducer

\begin{tabular}{ll}
\hline Parameter & Value \\
\hline Heat Exchanger & \\
Thickness & $2.5 \mathrm{~mm}$ \\
Length & $165 \mathrm{~mm}$ \\
Diameter & $60 \mathrm{~mm}$ \\
Material & Aluminum \\
Melting Point & $660^{\circ} \mathrm{C}$ \\
Flexibility & High \\
Durability & High \\
Strength & High \\
Reducer & \\
Thickness & $5 \mathrm{~mm}$ \\
Length & $200 \mathrm{~mm}$ \\
Diameter & $38.5 \mathrm{~mm}$ \\
Material & Aluminum \\
\hline
\end{tabular}

\subsection{Installation and Setup}

A test bench was set up to experiment and obtaining the power output from TEGs from waste heat recovery from an IC engine. The system is shown in the schematic diagram in Figure 4 . The hot source was supplied with a heat gun as the operation of a heat gun was interrelated with the actual performance of the exhaust engine for the experiment. The heat exchanger and reducer were insulated with a thermal insulator to minimize the heat loss. There were nine type-k thermocouple wires connected to the midi LOGGER GL220A. The thermocouples wires were connected to gain the reading of the temperature at the exact points. Besides, two thermoelectric generators had tested in this experiment connected to electronic load for gaining the output voltage and current reading produced by the TEGs. $12 \mathrm{~V}$ powered by DC power supply external fans as forced convection cooling with the help of heat sink was applied to the cold side of the TEGs. These external fans were fixed to the heat sink to achieve and maintain the temperature difference between the TEGs.

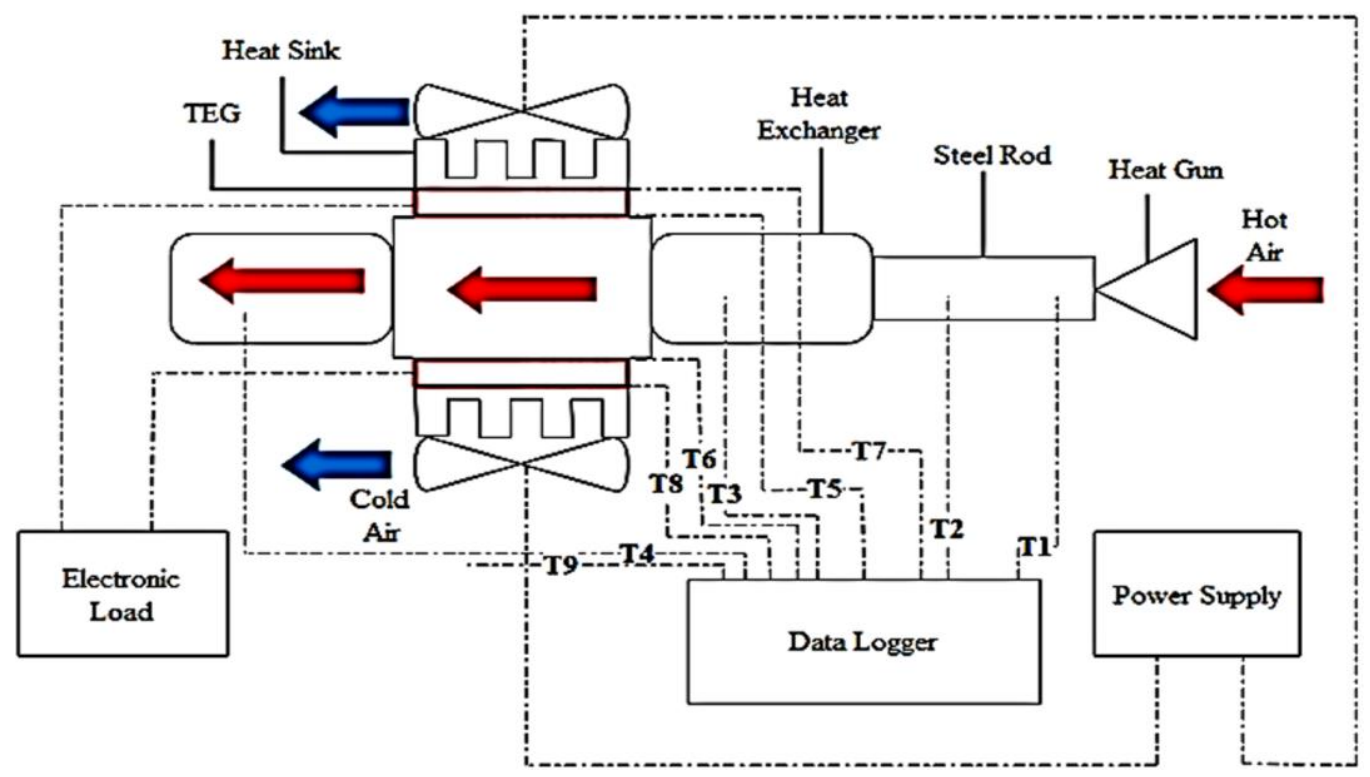

Fig. 4. Schematic diagram of the experimental setup 
The connection of individual TEGs, TEG 1, and TEG 2 was tested with four different waste heat source temperatures to identify the electrical characterization of each TEG. Waste heat sources were varied by changing the temperature of the heat gun. In addition, two TEGs also were tested in series and parallel electrical connections, as shown in Figure 5. The purpose of testing for different modes of connection was to recognize the differences in electrical characterization with different TEGs array configuration. Figure 6 shows the actual experimental setup used for the experimental study.

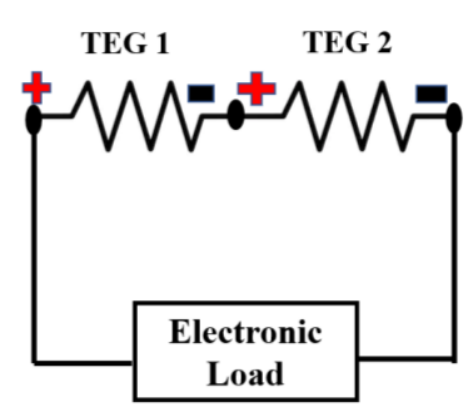

Series Connections

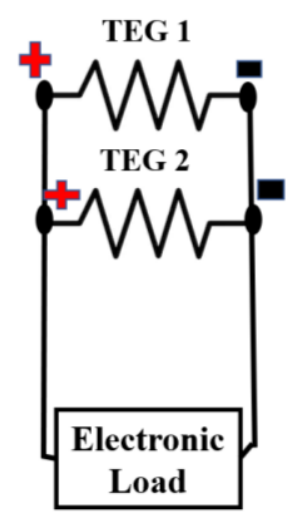

Parallel Connections

Fig. 5. Schematic diagram of TEG connections

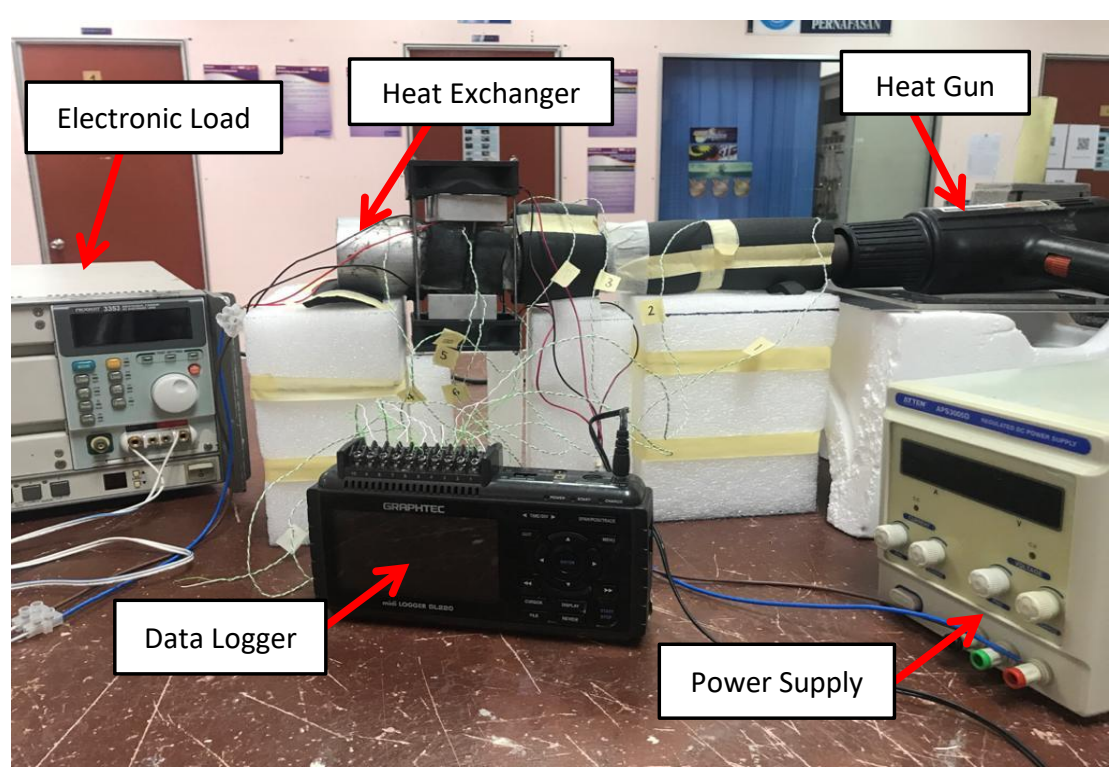

Fig. 6. Experimental setup

\section{Results}

In order to observe the differential change in electrical characterizations due to the addition of TEGs to the exhaust system, experiments were conducted on the test bench with individual TEG, series and parallel connections for both TEGs and the results were compared. In the test, the heat source temperature of the system was supplied at different values, $100^{\circ} \mathrm{C}, 150^{\circ} \mathrm{C}, 200^{\circ} \mathrm{C}$ and $250^{\circ} \mathrm{C}$, while the heat sink temperature was kept unchanged with $11.6 \mathrm{~V}$ supplied to the external fan for maximum rotation speed. The value of external load, $R_{L}$ electronic load was adjusted from $10 \Omega$ to $0.25 \Omega$, at the same time, the output voltage and current of the TEG system were carefully recorded using an electronic load. 


\subsection{Individual TEG}

Figure 7 and Figure 8 show the comparison results of output current and power of TEG 1, TEG 2 with respect to the output voltage. The current dropped consistently as the voltage increased in the system. TEG 1 achieved the maximum output current with 0.58 A while for TEG 2, it reached 0.342 A at $250{ }^{\circ} \mathrm{C}$, waste heat source temperature. After that, as illustrated in Figure 8 , the output power increased as the output voltage increased. The value of output power increased until it reached the maximum power point and then it started to decrease as shown in the figure. The output voltage generated was based on the temperature gradient which also produced current in the circuit. The output power was obtained and calculated based on formula P=IV. For TEG 1, at temperature of 250 ${ }^{\circ} \mathrm{C}$ recorded highest maximum power of $183 \mathrm{~mW}$. Then, TEG 2 obtained the highest maximum power at $250{ }^{\circ} \mathrm{C}$ with $71 \mathrm{~mW}$. It shows that TEG 1 had the best performance than TEG 2 due to the airflow of the heat source always going up due to buoyancy effect that produced a larger output voltage resulted in the higher maximum power. The curves showing the TEG maximum output power as a function of the temperature differential and the results are given respectively in Figure 9. The output power increased with an increase in a temperature difference $(\Delta T)$ across TEGs. This is due to an increase in waste heat source that resulted in an increase in power output. The highest maximum power of TEG 1 achieved at $32.6{ }^{\circ} \mathrm{C}$ of temperature difference meanwhile TEG 2 performed the highest value of MPP at $17.1^{\circ} \mathrm{C}$. It clearly shows that, the larger gap value between the TEG 1 and TEG 2 due to the arrangement of test bench that blocked the cooling airflow that resulted in the reduced output power of the system.

The heat transition along the inlet to outlet of heat exchanger based on the distance was measured and the result is as illustrated in Figure 10. For TEG 1 and TEG 2, the furthest distance point from heat source was $35 \mathrm{~cm}$ recorded only $153.1^{\circ} \mathrm{C}$ and $109.1^{\circ} \mathrm{C}$ of the temperature at $250{ }^{\circ} \mathrm{C}$ from heat source inlet. The results show that the heat is lost along with the distance of the transmission in the heat exchanger. The shortest distance from a heat source recorded was at $1.5 \mathrm{~cm}$ at $104.5^{\circ} \mathrm{C}$ and $115.9^{\circ} \mathrm{C}$ temperatures for TEG 1 and TEG 2 at $100^{\circ} \mathrm{C}$ heat source, respectively. The length of the heat exchanger resulted in drop of temperature in the flow channel. This affected the temperature difference that affected the voltage and power generated.

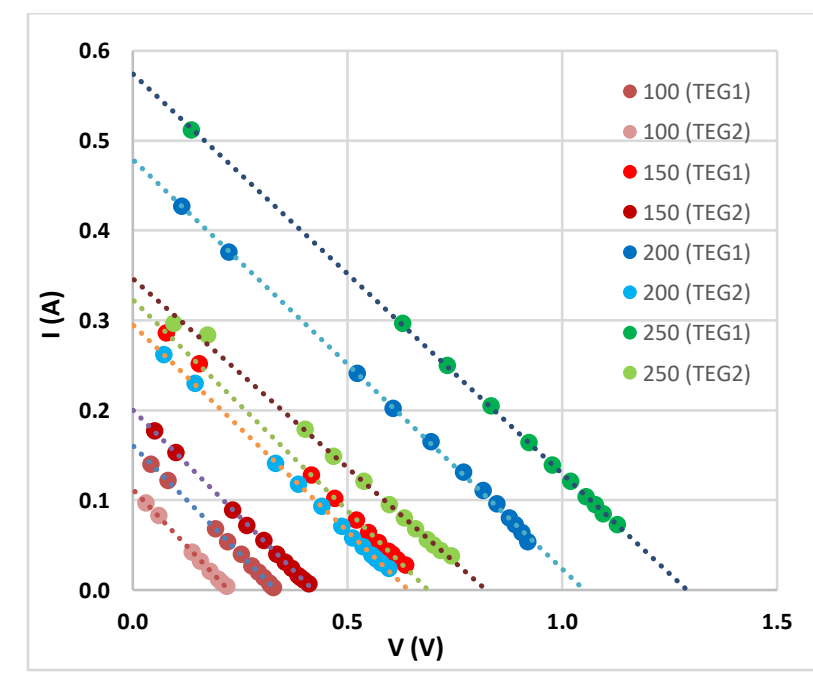

Fig. 7. Current profile of TEG 1 and TEG 2 


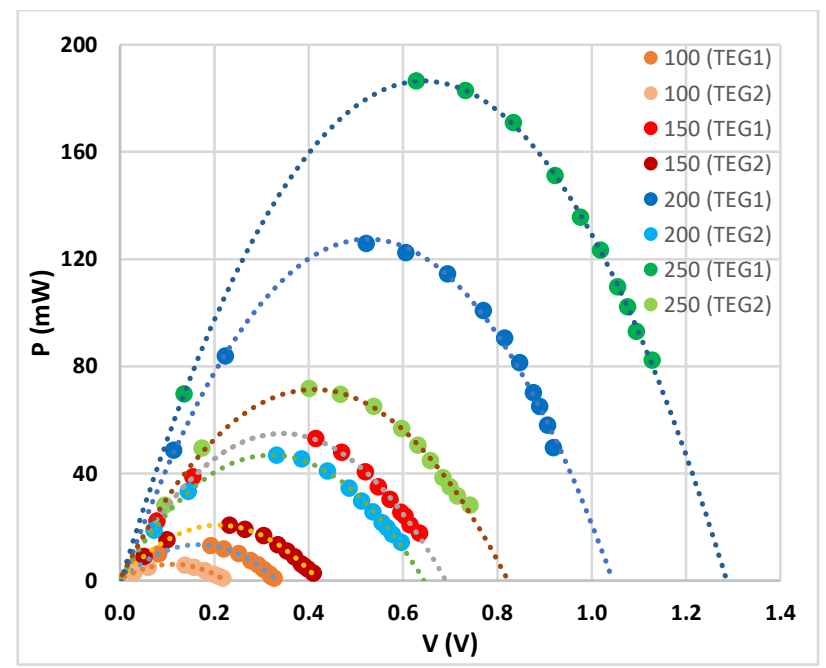

Fig. 8. Power output profile of TEG 1 and TEG 2

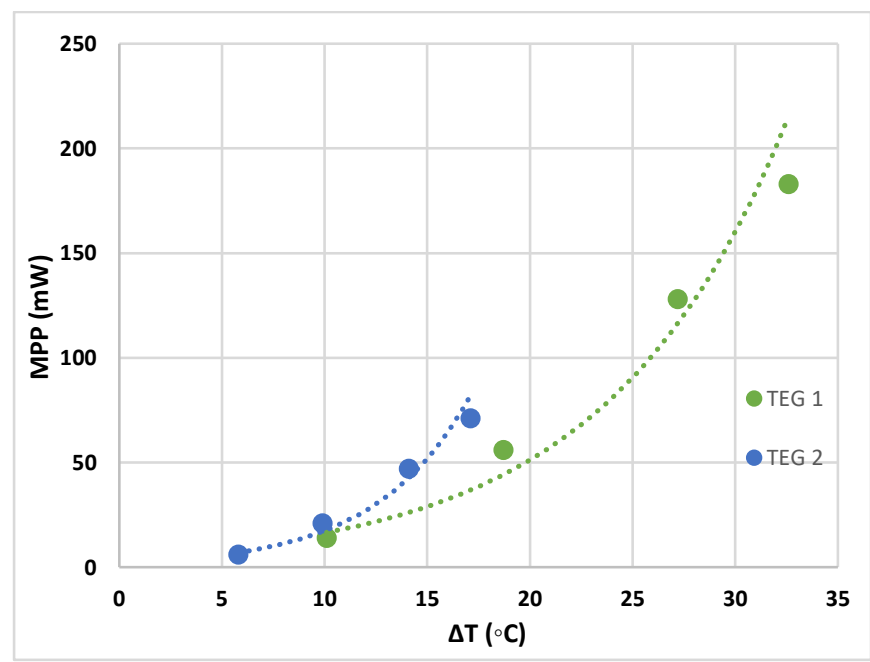

Fig. 9. Maximum power output at various temperature different of TEG 1 and TEG 2

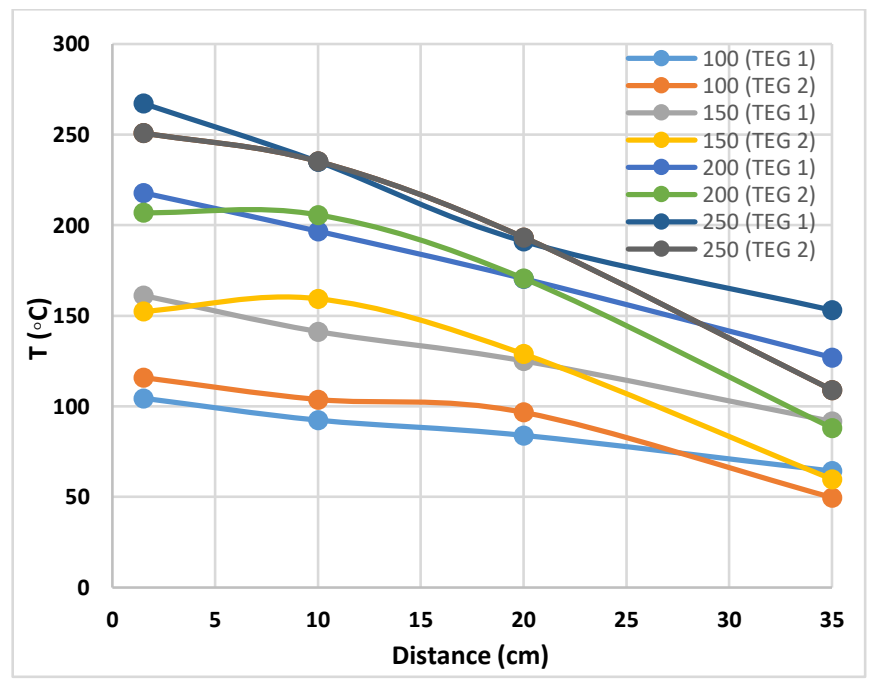

Fig. 10. Temperature along with the distance from heat source for TEG 1 and TEG 2 
The time taken for the voltage to achieve the steady-state is shown in Figure 11 . The voltage recorded in the open circuit stage when no external load was applied in the system. The average time for the voltage to achieve steady state for TEG 1 and TEG 2 was around 8 minutes. The longest time take by TEG 2 at $200{ }^{\circ} \mathrm{C}$ to achieve steady state was at 11 minutes.

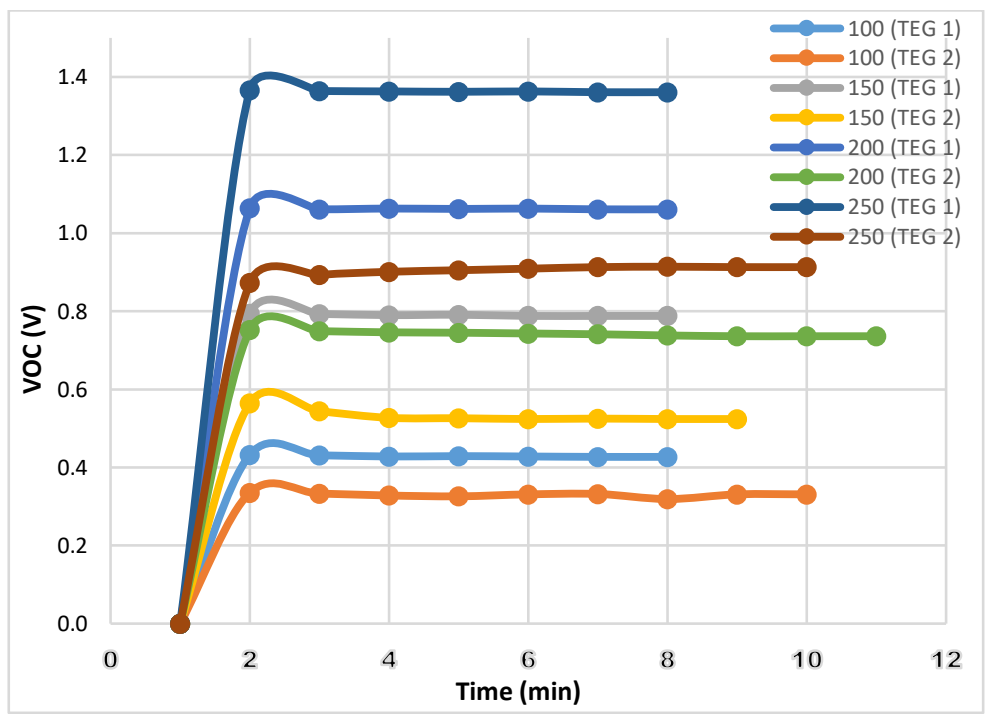

Fig. 11. Open circuit voltage against the time taken for TEG 1 and TEG 2

\subsection{Series and Parallel TEG}

The comparison of series and parallel TEG can be referred to in Figure 12 and Figure 13 based on current and power obtained from the TEG connections. It clearly shows that the performance of multi- TEGs is better than one TEG in the system. Based on Figure 12, the current decreased steadily as the output voltage increased. The maximum current obtained in series was at $0.48 \mathrm{~A}$ while in parallel was at $0.86 \mathrm{~A}$ at $250{ }^{\circ} \mathrm{C}$ waste heat source. By comparing the results of series and parallel TEGs, the electrical characteristics generated in the series were relatively in large voltage with a small current that leads to the electrical better efficiency of the system, since this will minimise electrical heating losses due to resistance. Therefore, the efficiency of the system will increase. Apart from that, the current produced by TEG in parallel array connection was higher with lower value of voltage.

As shown in Figure 13, the output power increased until it reached the maximum power point of the system. The value of the highest power output of series and the parallel connection was slightly different, with series connection at $252 \mathrm{~mW}$ while parallel connection at $250 \mathrm{~mW}$. The experimental results show the performance of the series TEG connection is better than a parallel connection in terms of power generation. However, parallel array is more reliable than series connections whereby the TEGs can still operate in the case of failure of other TEGs. If one of the TEG fails, the parallel pathway allows electricity to flow through another way compare to a series that only had one pathway of current to flow. It will not affect the other TEG if one of them failed in the connection. 


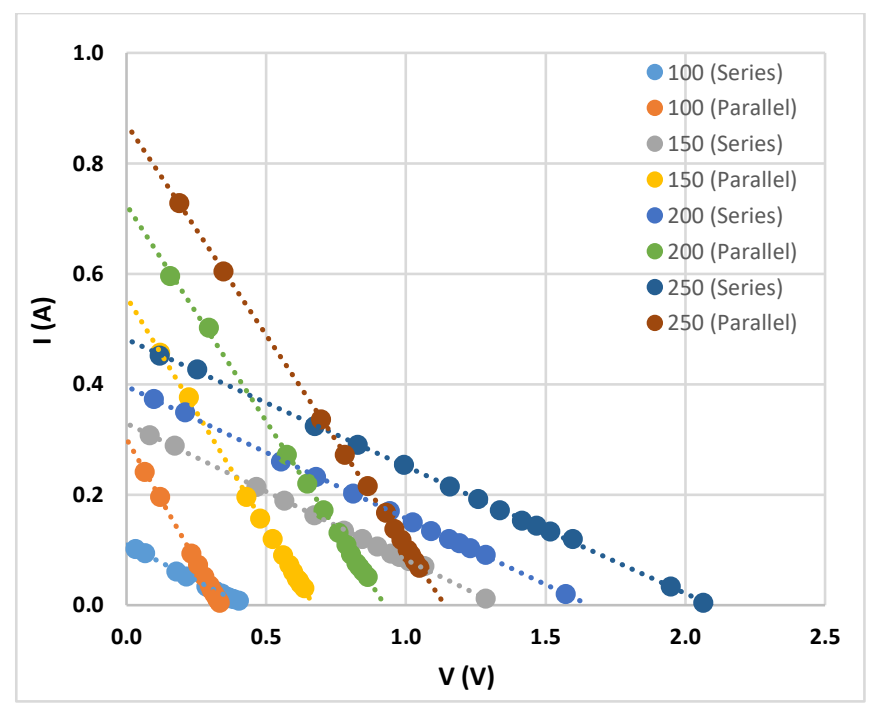

Fig. 12. Current profile of series and parallel TEG

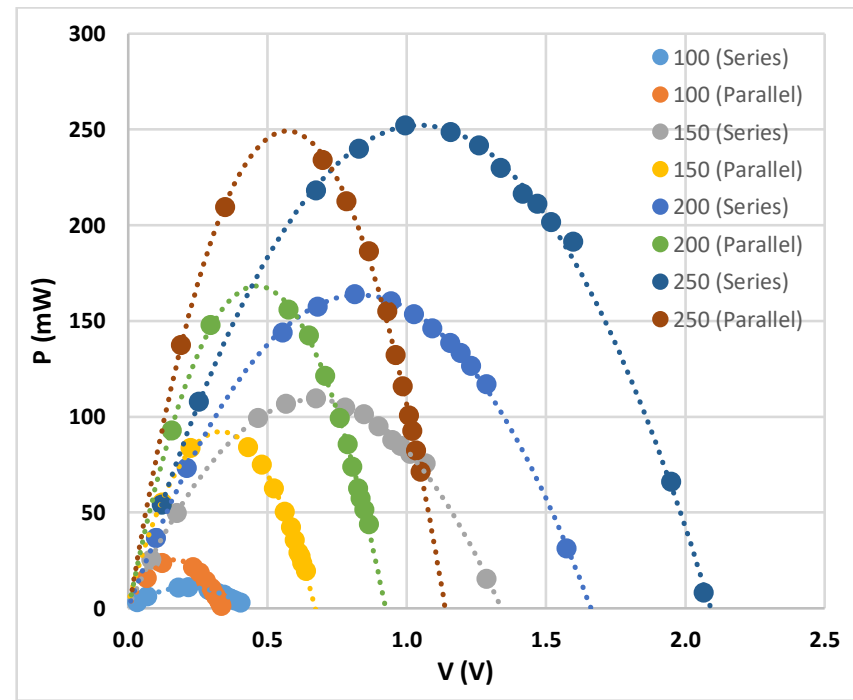

Fig. 13. Power output profile of series and parallel TEG

The maximum power output against temperature difference is shown in Figure 14. The curve shows that the larger the temperature difference between hot and cold side of TEG, the higher the maximum power output produced. The average temperature difference of TEG 1 and TEG 2 for series connection was at $23.55{ }^{\circ} \mathrm{C}$ resulted in the highest output power at $252 \mathrm{~mW}$. The average temperature difference of series and parallel connection only differ in small value.

Heat transmitted along the heat exchanger decreased as the distance increased from the heat source as shown in Figure 15, for series and parallel TEG. For a parallel connection, the heat at the entry of heat exchanger was at $253.2{ }^{\circ} \mathrm{C}$ and at the outlet was at $171.2{ }^{\circ} \mathrm{C}$. The difference of this temperature was contributed by the length of the heat exchanger at $33.5 \mathrm{~cm}$.

The time taken for series and parallel TEG to reach in steady-state is shown in Figure 16. It shows that the voltage took about 11 minutes to achieve the steady-state when no external load was applied in the system. The maximum time was at 12 minutes for parallel TEG while the minimum time taken was 10 minutes for series TEG to achieve the steady-state. 


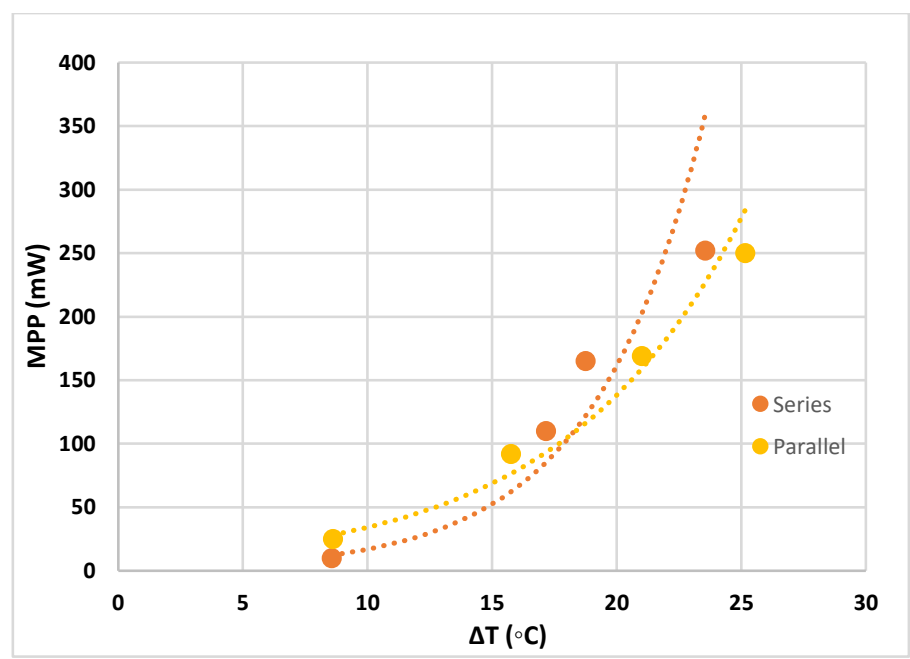

Fig. 14. Maximum power output at a various temperature different of series and parallel TEG

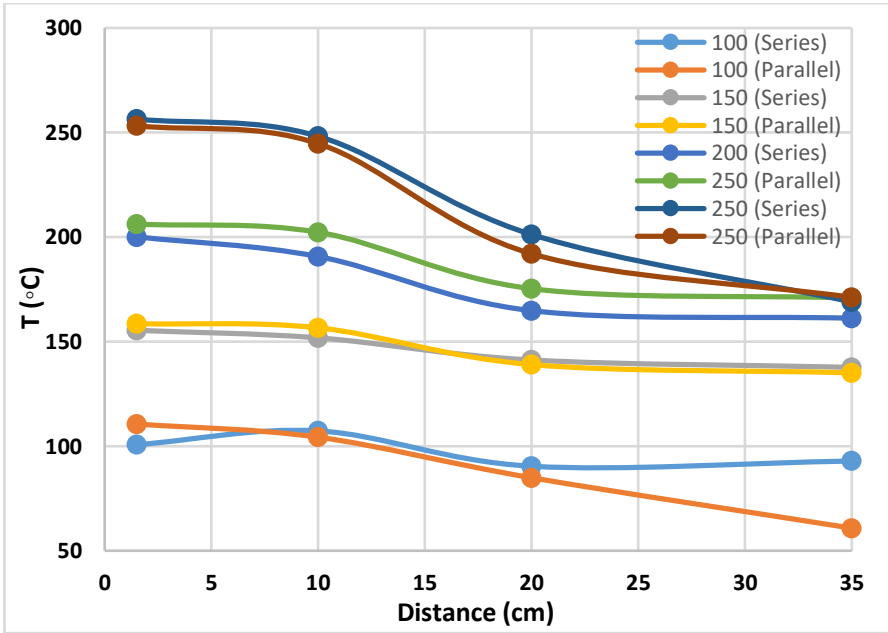

Fig. 15. Temperature along with the distance from heat source for series and parallel TEG

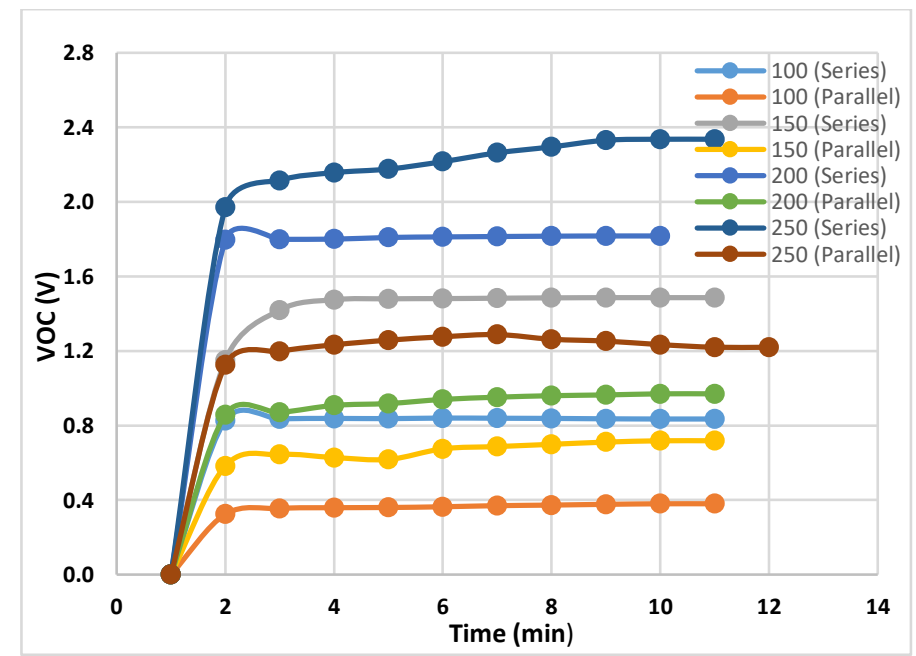

Fig. 16. Open circuit voltage against the time taken for series and parallel TEG 


\section{Conclusions}

In conclusion, the power generation analysis by using a thermoelectric generator was conducted for a waste heat recovery system in the internal combustion engine. The project had achieved the objectives outlined. From this project, it shows that multi-TEG in the system gave the best result of electrical characterization compared to individual TEG. From the experiment, TEG 1 performed well than TEG 2 because of the location position of the TEG. From the experiment, TEG 1 was able to obtain $183 \mathrm{~mW}$ of maximum power output at $250{ }^{\circ} \mathrm{C}$ hot temperature. TEG1 performed better than TEG 2 due to buoyancy effect that channelled most heat to the top TEG 1 . The series connection proved that it achieved a higher voltage in the system that resulted in the highest maximum power output. The series TEG connection achieved the maximum power output at $252 \mathrm{~mW}$ for $250{ }^{\circ} \mathrm{C}$ hot temperature. However, the system of parallel array configuration is deemed to be more reliable than the series TEG. Moreover, the distance of point measured from the heat source also affected the temperature obtained. The heat along the system will decrease as the distance increased. The location of TEG was $20.75 \mathrm{~cm}$ from the inlet of the waste heat source. It affected the range of temperature differences that resulted in voltage and power generated. TEG was able to receive 80.1 ${ }^{\circ} \mathrm{C}$ of maximum hot temperature and $58.1^{\circ} \mathrm{C}$ of cold temperature that supplied from air cooling.

\section{Recommendations}

These recommendations are suggested towards the improvement of the project to enhance better performance and result. The proposal as follows

i. The temperature of the waste heat source needs to be enlarged in producing a large temperature difference of TEG.

ii. Add more thermoelectric generator (TEG) to induce the maximum power of the system.

iii. Develop a new reducer attached to a heat exchanger to increase the airflow of the heat source.

iv. Improve a new heat exchanger attached with swirl nozzle at the inlet to increase the speed and turbulence of the air.

v. Improve the test bench to allow the cooling airflow that gives better cooling modes for the TEG.

vi. Use proper and stable heat source to supply the waste heat source that eases to handle and control the parameter.

\section{Acknowledgement}

This research was funded by a grant from Universiti Teknologi MARA, Malaysia under Research Entity Initiative (REI) Grant (600-IRMI/DANA 5/3/REI (003/2018)).

\section{References}

[1] Milkov, Nikolay, T. Evtimov, and P. Plamen. "Advanced Technologies For Waste Heat Recovery In Internal Combustion Engines." Machines Technologies Materials 9, no. 8 (2015): 60-66.

[2] Chinguwa, Simon, Christopher Musora, and Tawanda Mushiri. "The design of portable automobile refrigerator powered by exhaust heat using thermoelectric." Procedia Manufacturing 21 (2018): 741-748. https://doi.org/10.1016/i.promfg.2018.02.179

[3] Ibrahim, Nurru Anida, Idrus Salimi Ismail, Siti Norbakyah Jabar, and Salisa Abdul Rahman. "A Study on the Effects of Plug-In Hybrid Electric Vehicle (PHEV) Powertrain on Fuel Consumption, Electric Consumption and Emission using Autonomie." Journal of Advanced Research in Applied Sciences and Engineering Technology 16, no. 1 (2019): 4956. 
[4] Endo, Tsuneo, Shogo Kawajiri, Yoichi Kojima, Kazuya Takahashi, Tsuyoshi Baba, Shigeru Ibaraki, Tsutomu Takahashi, and M. Shinohara. "Study on maximizing exergy in automotive engines." SAE Transactions (2007): 347-356. https://doi.org/10.4271/2007-01-0257

[5] Rey, Denzil. "How hot can car exhaust get?" Wheelsjoint.com, June 2, 2020. https://www.wheelsjoint.com/howhot-can-a-car-exhaust-get/

[6] Jouhara, Hussam, Navid Khordehgah, Sulaiman Almahmoud, Bertrand Delpech, Amisha Chauhan, and Savvas A. Tassou. "Waste heat recovery technologies and applications." Thermal Science and Engineering Progress 6 (2018): 268-289. https://doi.org/10.1016/i.tsep.2018.04.017

[7] Soni, Lakshya, Pawan Kumar, and Rahul Goyal. "A Review on Waste Heat Recovery From Domestic Refrigerator." Imperial Journal Of Interdisciplinary Research (IJIR) 2, no. 8 (2016): 667-670.

[8] Abd Jalil, Mohd Izam, and Jahariah Sampe. "Experimental investigation of thermoelectric generator modules with different technique of cooling system." American Journal of Engineering and Applied Sciences 6, no. 1 (2013): 1-7. https://doi.org/10.3844/ajeassp.2013.1.7

[9] Kumar, Ramesh C., Ankit Sonthalia, and Rahul Goel. "Experimental study on waste heat recovery from an IC engine using thermoelectric technology." Thermal Science 15, no. 4 (2011): 1011-1022. https://doi.org/10.2298/TSCI100518053K

[10] Ismail, H., A. A. Aziz, R. A. Rasih, N. Jenal, Z. Michael, and Azmi Roslan. "Performance of Organic Rankine Cycle Using Biomass As Source of Fuel." Journal of Advanced Research in Applied Sciences and Engineering Technology 4, no. 1 (2016): 29-46.

[11] Kim, Shiho, Soonseo Park, Sunkook Kim, and Seok-Ho Rhi. "A thermoelectric generator using engine coolant for light-duty internal combustion engine-powered vehicles." Journal of Electronic Materials 40, no. 5 (2011): 812-816. https://doi.org/10.1007/s11664-011-1580-6

[12] Brito, F. P., Jorge Martins, L. M. Goncalves, Nuno Antunes, and Diogo Sousa. "Influence of Heat Pipe Operating Temperature on Exhaust Heat Thermoelectric Generation." SAE International Journal of Passenger Cars-Mechanical Systems 6, no. 2013-01-0559 (2013): 652-664. https://doi.org/10.4271/2013-01-0559

[13] Brito, F. P., Jorge Martins, Esra Hançer, Nuno Antunes, and L. M. Gonçalves. "Thermoelectric exhaust heat recovery with heat pipe-based thermal control." Journal of Electronic Materials 44, no. 6 (2015): 1984-1997. https://doi.org/10.1007/s11664-015-3638-3

[14] Martins, Jorge, L. M. Goncalves, Joaquim Antunes, and Francisco P. Brito. Thermoelectric Exhaust Energy Recovery with Temperature Control through Heat Pipes. No. 2011-01-0315. SAE Technical Paper, 2011. https://doi.org/10.4271/2011-01-0315

[15] Love, N. D., James P. Szybist, and Charles S. Sluder. "Effect of heat exchanger material and fouling on thermoelectric exhaust heat recovery." Applied Energy 89, no. 1 (2012): 322-328.

[16] Karuppaiah, Aravind, Ganesh S., Dileepan T., and Jayabharathi S. "Fabrication and Analysis of Thermo Electric Generator For Power Generator." International Journal of Innovative Research in Science, Engineering and Technology 3, no. 1 (2014): 1508-1513.

[17] Chandy, Rohan Mathai, Rakesh Rajeev, Richu Lonappan Jose, and Thomas Lukose. "Design and Analysis of Heat Exchanger for Automotive Exhaust based Thermoelectric Generator [TEG]." IJIRST - International Journal for Innovative Research in Science \& Technology 1, no. 11 (2015): 291-298.

[18] Liu, Xun, Y. D. Deng, Zhi Li, and C. Q. Su. "Performance analysis of a waste heat recovery thermoelectric generation system for automotive application." Energy Conversion and Management 90 (2015): 121-127. https://doi.org/10.1016/i.enconman.2014.11.015 